\title{
Synthesis of Al-Fly Ash Composites by Modified Two Step Stir Casting
}

\section{Method}

\author{
P.Shanmughasundaram ${ }^{1, a}$, R.Subramanian ${ }^{2, ~ b}$, G.Prabhu $^{3, c}$ \\ ${ }^{1}$ Department of Mechanical Engineering, Karpagam College of Engineering, Coimbatore-641032. \\ ${ }^{2}$ Department of Metallurgy, PSG College of Technology,Coimbatore-641004. \\ ${ }^{3}$ Department of Automobile Engineering, Karpagam University, Coimbatore-641021. \\ asunramlec@rediffmail.com; 'btruppursubbu@gmail.com; cprabhuapg@yahoo.co.in
}

\begin{abstract}
Keywords: Composites; Fly ash; Modified two step stir casting ; Taguchi
\end{abstract}
\begin{abstract}
In the stir casting process, homogeneous dispersion of reinforcing particles within the matrix material is one such major problem, which influences on the properties of composites. In this research, an attempt has been made to study the influence of fly ash wt.\% (10,15 and 20), ratio of the impeller outer dia to crucible inner dia (0.7,0.5 and 0.3) and processing method (liquid state stirring, two step stirring and modified two step stirring) on the mechanical properties and the distribution of fly ash particles in the $\mathrm{Al}$ matrix.Optimum parameters were identified for attaining the maximum mechanical properties such as hardness and tensile strength of composites by the application of Taguchi method, Analysis of Variance (ANOVA) and the results were validated by confirmation test.The present work could provide a guide for the industrial preparation of composites.
\end{abstract}

\section{Introduction}

Aluminium Matrix Composites (AMCs) have attracted more attention due to their combined properties such as high specific strength, high stiffness, low thermal expansion coefficient and superior dimensional stability at elevated temperatures as compared to the monolithic materials. In this study, fly ash particles which are extracted from residues generated in the combustion of coal were chosen as reinforcement material.

Stir casting process appears to be most promising method for manufacturing of aluminium matrix composites because of simplicity and ability to produce the composites in large scale economically and commercially.Mahendra and Radhakrishna [1] investigated the properties of $\mathrm{Al}$ $4.5 \% \mathrm{Cu}$ alloy composite with fly ash as reinforcement and have reported that the increase in hardness, tensile and compression and impact strength with increase in the fly ash content.Sarkar and co researchers [2] have studied on Al- fly ash composite produced by impeller mixing and concluded that up to $17 \mathrm{wt}$. \% fly ash can be reinforced by liquid metallurgy route and also the addition of magnesium increases the wettability which enhances wear resistance, mechanical properties such as hardness and tensile strength.Rohatgi and co authors [3] have suggested that Alfly composites can be used for automotive and other applications due to their better mechanical properties.

The major difficulty in the processing of composite material through the stir casting process is to obtain homogenous dispersion of reinforcing particles in the matrix for improving its microstructure and enhancing the mechanical properties.In order to achieve the optimum properties of the metal matrix composite, several factors that have to be considered, including the achieving a uniform distribution of the reinforcement material in molten matrix, improving the wettability or bonding between the matrix and reinforcement, enhancing the solid solution strengthening mechanism by interfacial chemical reactions and minimizing the porosity [4].

The magnesium which acts as a powerful surfactant as well as a reactive element, in the $\mathrm{Al}$ matrix seems to enhance the wettability. The important role played by the magnesium during the 
composite synthesis is the scavenging of the oxygen from the dispersoid surface, thus thinning the gas layer and improving wetting action with the matrix material [4].

Homogeneous distribution of solid reinforcements in the molten matrix depends on the flow behavior of the composite slurry during stirring. Since the stir casting process is carried out in a closed crucible, the effect of the stirring action on the flow pattern is invisible.Various researchers [ 5,6 ] have conducted visualization (simulation) experiments in order to predict the distribution of reinforcement particles in the matrix. Rohatgi and co authors [5] have conducted a study on the mixing quality of two phase slurries using $\mathrm{SiC}$-water system to determine the influence of impeller geometry on the uniformity of distribution of SiC.The degree of stirring depends on various factors, such as the type and shape of the impeller, and its location relative to the molten surface as well as the wall of the crucible, stirring speed and time. According to the previous study [4], it was found that 15 minutes stirring time with $300 \mathrm{rpm}$ stirring speed showed good result in micro structure and mechanical properties as well. Ghosh and Ray [7] have studied the influence of process parameters of the size and position of the impeller on the development of porosity.Aniban and co researchers [8] have attempted to analyze some of the different impeller parameters such as type, diameter and width utilized for Al MMC synthesis against the theoretical values based on chemical engineering principles.Various investigators [9,10] have used both axial and radial flow impellers for the synthesis of MMC.Amongst axial and radial flow impellers, radial flow impeller which imposes essentially shear stress to the fluid ,could be used for mixing of high viscous fluids.It creates a radial flow pattern moving away from the impeller and overcomes the cohesive force of the solid dendrites and disperses it into the individual particles.So 4 bladed radial impeller was selected in this study.

Hence it is necessary for a systematic study the influence of process parameters such as processing method and the ratio of impeller outer dia to the crucible inner dia on the distribution of fly ash particles in molten $\mathrm{Al}$ and mechanical properties of composites which are fabricated by stir casting method. The primary objective of this study is to use Taguchi method for predicting the optimum process parameters that give the highest hardness and tensile strength to the composites.

\section{Composite Preparation}

In this study, 99.5\% pure aluminium ingot was used as the matrix material and fly ash particles with average size of $(50-100 \mu \mathrm{m})$ was used as the reinforcement which consists of $\mathrm{SiO}_{2}-54.27 \%, \mathrm{Al}_{2} \mathrm{O}_{3}$ $34.73 \%, \mathrm{Fe}_{2} \mathrm{O}_{3}-6.1 \%, \mathrm{CaO}-2.4 \%, \mathrm{MgO}-2.1 \%$.

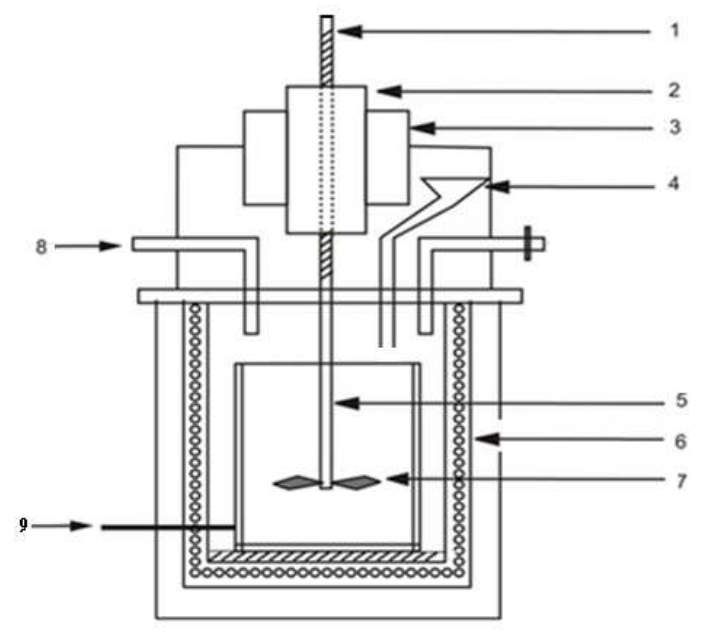

\section{Stirrer spindle}

2. Sliding mechanism with impeller position control unit

3.Electric motor

4.Sprue

5. Stirrer spindle

6.Electric furnace

7. Impeller

8.Argon gas inlet

9.Thermocouple

Fig. 1 Modified two stepstir casting setup 
In this research, Al - fly ash composites were produced by stir casting method. A schematic of the stir casting experimental setup is shown in Fig. 1. The capacity of an electric resistive furnace is $2 \mathrm{Kw}$ ( $2 \mathrm{Kg}$ capacity).Temperatures are measured with a thermocouple (+/-3 K error).Composites were prepared in three different stirring methods according to the Taguchi orthogonal L9 array as shown in Table 1.The nature of the each stirring procedure is mentioned below.

The fly ash particles were preheated to $600^{\circ} \mathrm{C}$ for 2 hours in a separate muffle furnace to remove the moisture content. In addition, air absorbed on the surface of fly ash particles, which was prepared in air, can also be removed. Hexachloroethane tablets were used for degassing and argon gas was blown at the rate of $2 \mathrm{CC} / \mathrm{min}$ in to the furnace during the process to minimize the high temperature oxidation problems of $\mathrm{Al}$ and $\mathrm{Mg}$. Al was charged in to the graphite crucible (flat bottom type) and the furnace temperature was raised up to liquidus temperature $670^{\circ} \mathrm{C}$ in order to melt the $\mathrm{Al}$ scraps completely.Initial stirring was started at $300 \mathrm{rpm}$ to generate vortex and preheated fly ash particles was added.1.5wt.\% magnesium was also added into the molten Al to promote the wetting action between $\mathrm{Al}$ matrix and fly ash particles.

Liquid State Stirring:In this method,stirring took place when the composite slurry was in complete liquid state for 15 minutes and finally the slurry was poured in a mould to solidify.

Two Step Stirring : In this method, first step stirring took place after the melt temperature was dropped to $620^{\circ} \mathrm{C}$ to obtain the semi- solid state for 10 minutes. Then the slurry was reheated to liquidus temperature of $\mathrm{Al}$ and the second step stirring was started in a liquid state for 5 minutes until the slurry was poured in a mould to solidify.In both the processes impeller was placed $1 / 3^{\text {rd }}$ height from the bottom of the crucible.

Modified Two Step Stirring Method : In this method ,the same two step procedure was adopted but the impeller was frequently moved vertically within the slurry at the rate of $2 \mathrm{~mm} / \mathrm{s}$ by means of stirrer position control unit during stirring process,as shown in Fig.1. A specially designed sliding mechanism was employed to facilitate the reciprocating motion of the impeller within the slurry along with stirrer assembly.Thus, rotary as well as reciprocating movement of impeller in the composite slurry was done during stirring. Finally the composite slurry was poured into the steel mould to solidify.

\section{Results}

\section{Mechanical Properties}

The hardness value of the specimens was measured using Brinell hardness testing system with $10 \mathrm{~mm}$ diameter at a load of $500 \mathrm{~kg}$. The loading time was 30 seconds. Three readings were taken on each specimen to eliminate possibility of segregation and mean value was taken as the hardness of the composite.Tensile test was carried out on the specimens using a computerized UTM testing machine as per the ASTM E-8 standards. Three samples were tested for each composition and mean value was taken as the tensile strength.

\section{Design of Experiments (DOE)}

Taguchi's parameter design provides a systematic and efficient methodology for determining optimum parameters which have an effect on the process and performance. It eliminates the need for repeated experiments and thus saves time, material and cost.By studying the effect of individual factors on the results, the combination of optimum parameters can be determined. In the Taguchi method, the term 'signal' expresses the desirable value (mean) and the term 'noise' expresses the undesirable value (standard deviation) for the output quality characteristics. The mean $\mathrm{S} / \mathrm{N}$ ratio for each level is the measure of quality characteristics deviating from the desired value and provides a measure of the impact of noise factors on performance. In the present work, "Larger is better" S/N ratio is used to predict the optimum parameters because a higher hardness and tensile strength of the composites was desirable. In the present investigation, hardness and tensile strength tests were 
conducted in the composite material as per the L9 orthogonal array. Accordingly, 9 experiments were carried out and each experiment was repeated thrice in order to minimize the experimental errors. The factors and the corresponding levels which have been used are presented in Table 1.

Table 1.Factors and levels

\begin{tabular}{|c|c|c|c|}
\hline Level & $\begin{array}{c}\text { Fly ash wt.\% } \\
(\mathrm{A})\end{array}$ & $\begin{array}{c}\mathrm{C}_{\mathrm{ID}} / \mathrm{I}_{\mathrm{OD}} \text { ratio } \\
(\mathrm{B})\end{array}$ & $\begin{array}{c}\text { Processing method } \\
(\mathrm{C})\end{array}$ \\
\hline I & 10 & 0.7 & Liquid state (1) \\
\hline II & 15 & 0.5 & Two step (2) \\
\hline III & 20 & 0.3 & Modified two step (3) \\
\hline
\end{tabular}

Table 2 S/N ratios and measured values for hardness and tensile strength of composites

\begin{tabular}{|c|c|c|c|c|c|c|c|}
\hline Exp & Flyash & \multirow{2}{*}{$\begin{array}{l}\mathrm{C}_{\mathrm{ID}} / \mathrm{I}_{\mathrm{OD}} \\
\text { No }\end{array}$} & $\begin{array}{c}\text { Pt.\% } \\
\text { ratio }\end{array}$ & $\begin{array}{c}\text { Processing } \\
\text { Method }\end{array}$ & \multicolumn{2}{|c|}{ Signal/Noise Ratio } & \multicolumn{2}{c|}{ Measured Values } \\
\cline { 5 - 8 } & $(\mathrm{B})$ & $(\mathrm{C})$ & Hardness & $\begin{array}{c}\text { Tensile } \\
\text { strength }\end{array}$ & $\begin{array}{c}\text { Hardness } \\
(\mathrm{BHN})\end{array}$ & $\begin{array}{c}\text { Tensile } \\
\text { strength(Mpa) }\end{array}$ \\
\hline 1 & 10 & 0.7 & 1 & 24.609 & 40.423 & 17 & 105 \\
\hline 2 & 10 & 0.5 & 2 & 27.234 & 40.748 & 23 & 109 \\
\hline 3 & 10 & 0.3 & 3 & 26.444 & 40.506 & 21 & 106 \\
\hline 4 & 15 & 0.7 & 2 & 31.126 & 41.798 & 36 & 123 \\
\hline 5 & 15 & 0.5 & 3 & 31.595 & 41.727 & 38 & 122 \\
\hline 6 & 15 & 0.3 & 1 & 25.105 & 41.061 & 18 & 113 \\
\hline 7 & 20 & 0.7 & 3 & 34.807 & 41.214 & 55 & 115 \\
\hline 8 & 20 & 0.5 & 1 & 30.881 & 40.506 & 35 & 106 \\
\hline 9 & 20 & 0.3 & 2 & 32.465 & 40.668 & 42 & 108 \\
\hline
\end{tabular}

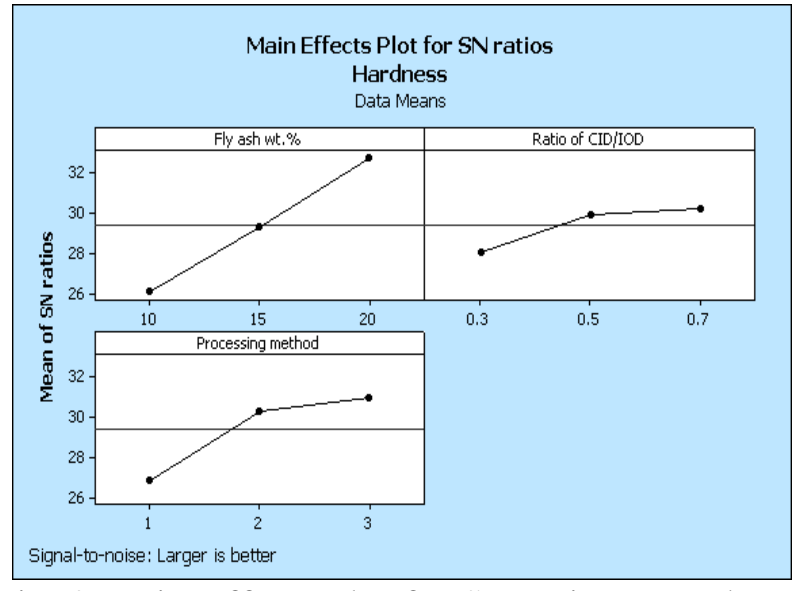

Fig. 2 Main Effects plot for SN ratios - Hardness

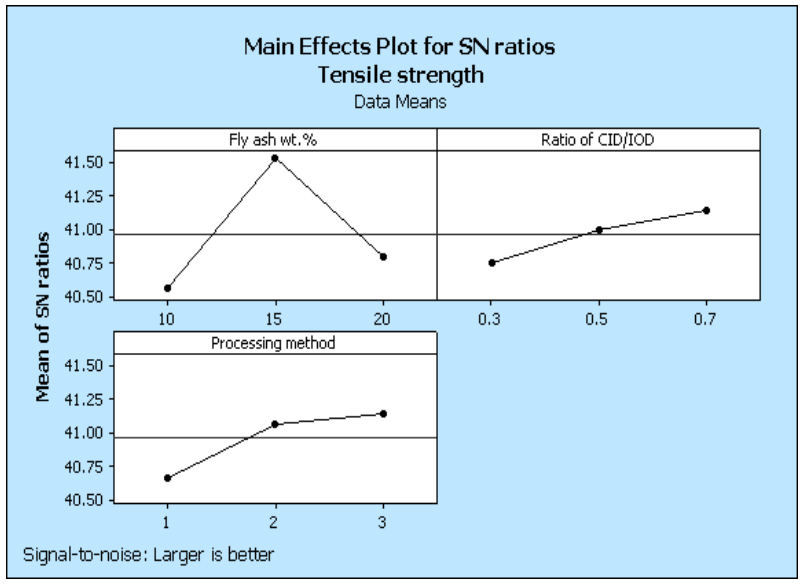

Fig. 3 Main Effects plot for $\mathrm{SN}$ ratios Tensile strength

Table 3. ANOVA analysis for Hardness and Tensile strength

\begin{tabular}{|l|c|c|c|c|c|c|c|}
\hline \multirow{2}{*}{ Factors } & \multirow{2}{*}{ Dof } & \multicolumn{3}{c|}{ Hardness } & \multicolumn{3}{c|}{ Tensile strength } \\
\cline { 3 - 8 } & & $\mathrm{F}$ & P value & Pc\% & F & P value & Pc\% \\
\hline Flyash wt.\% (A) & 2 & 181 & 0.005 & 64.28 & 295.75 & 0.003 & 69.68 \\
\hline $\mathrm{C}_{\mathrm{ID}} / \mathrm{I}_{\mathrm{OD}}$ ratio (B) & 2 & 26.14 & 0.037 & 9.28 & 49 & 0.020 & 11.54 \\
\hline Processing method (C) & 2 & 73 & 0.014 & 25.92 & 78.25 & 0.013 & 18.43 \\
\hline Error & 2 & & & 0.52 & & & 0.34 \\
\hline
\end{tabular}

Dof- Degree of freedom; Pc-Percentage of contribution 
Results of S/N Ratio: The S/N ratio for each parameter level is determined by averaging the $\mathrm{S} / \mathrm{N}$ ratios at the corresponding level. Process parameters with the highest $\mathrm{S} / \mathrm{N}$ ratio would give the optimum quality with minimum variance. From the table. 2 and response diagrams of $\mathrm{S} / \mathrm{N}$ ratio (Fig. 2 and Fig. 3), it was found that the optimum parameters were fly ash wt.\% (20\% for hardness and $15 \mathrm{wt} . \%$ for tensile strength), ratio of $\mathrm{C}_{\mathrm{ID}} / \mathrm{I}_{\mathrm{OD}}(0.7)$ and processing method (modified two step).

Results of ANOVA: ANOVA determines the optimum combination of process parameters more accurately by investigating the relative importance among the parameters. ANOVA was performed with the help of the software package MINITAB15 for a level of significance of 5\% to study the contribution of the factors. In the ANOVA table, there is a P-value for each independent parameter in the model. When the P-value is less than 0.05 , then the parameter can be considered as statistically highly significant. It is observed that, all the three factors have less than 0.05 , which means that they are highly significant at $95 \%$ confidence level. The last column of the table 3 shows the percentage contribution (Pc \%) of each variable in the total variation indicating their degree of influence on the mechanical properties. It can be observed that the fly ash wt.\% (64.28\%) was the major contributing factor followed by processing method (25.92\%) and finally ratio of impeller OD/ crucible ID (9.28\%) influencing the hardness of the composites. The same trend was observed for the tensile strength of the composites. From the outcome of S/N ratio and ANOVA, it can be inferred that the results are closely matches with each other.

Multiple Linear Regression Models: A multiple linear regression equation was developed to establish the correlation among the significant factors on the response. The value of regression coefficient, $\mathrm{R}^{2}(0.9964)$ is in good agreement with the adjusted $\mathrm{R}^{2}(0.9858)$ for hardness and $\mathrm{R}^{2}$ (0.9976) is in good agreement with the adjusted $R^{2}(0.9906)$ for tensile strength. Since both the values are reasonably close to unity, models provide reasonably good explanation of the relationship between the independent factors and the response (properties).

The regression equation developed for hardness is

Hardness $=-29.7+2.37 \mathrm{~A}+22.5 \mathrm{~B}+7.33 \mathrm{C}$

Eq. 1

The regression equation developed for tensile strength is

Tensile strength $=94.4+0.3 \mathrm{~A}+13.3 \mathrm{~B}+3.17 \mathrm{C}$

Eq. 2

From the Eqn. (1) and Eqn. (2), it is observed that the fly ash wt. \% (A) plays a major role on hardness and tensile strength followed by the processing method $(C)$ and ratio of $\mathrm{C}_{\mathrm{ID}} / \mathrm{I}_{\mathrm{OD}}(\mathrm{B})$.

Confirmation Test: A confirmation test is the final step in the design of experiment process. It was found that the optimum parameters were fly ash wt. \% (20\%), $\mathrm{I}_{\mathrm{OD}} / \mathrm{C}_{\mathrm{ID}}$ ratio $(0.7)$, and processing method (modified two step) for the hardness whereas fly ash wt. $\%(15 \%), \mathrm{I}_{\mathrm{OD}} / \mathrm{C}_{\mathrm{ID}}$ ratio $(0.7)$ and processing method (modified two step) for the tensile strength of composites. The confirmation experiments were conducted for the optimum parameters. Best results (maximum hardness $55 \mathrm{BHN}$ and tensile strength $126 \mathrm{MPa}$ ) were found and comparison was made with computed values developed from the regression model. Experimental values and calculated values for hardness and tensile strength from the regression equation are nearly same with least error $( \pm 6 \%)$. The resulting equations seem to be capable of predicting the mechanical properties to the acceptable level of accuracy. However if number of observations of performance characteristics are increased further these errors can be reduced.

\section{Discussion}

As seen from Table 3, the optimum value of the fly ash content found for obtaining the maximum hardness and tensile strength of the composite are $20 \mathrm{wt} \%$ and $15 \mathrm{wt} \%$ respectively.

It can be observed that as fly ash content increases the hardness of composite increases. It can be explained by the fact that the fly ash particles possess higher hardness than the aluminum. Tensile 
strength of unreinforced $\mathrm{Al}$ is $77 \mathrm{MPa}$ and this value increases to a maximum of $126 \mathrm{MPa}$ for $\mathrm{Al}-15$ wt\% fly ash composite which is about $39 \%$ improvement over that of the unreinforced Al matrix. When the fly ash content is more than $15 \mathrm{wt} . \%$, tensile strength started decreasing. It could be due to clustering of the fly ash particles.

It can be observed from the ANOVA analysis (Table 3) that the modified two step stirring method has significant influence on mechanical properties of the composites. Rotary as well as reciprocating movement of impeller prevents the settling of wetted fly ash particles at the bottom of the crucible and maintains the particles in a state of suspension which enhances the uniform distribution. Hence the modified processing ensures the uniform distribution of fly ash particles in $\mathrm{Al}$ matrix and enhances the mechanical properties.

It can be noted that the liquid state stirring could not solve the problem of poor wetting. Because when the stirring is stopped the fly ash particles tended to return to the molten surface due to its higher surface tension. Also two step stir casting method has some shortcomings. When the first step stirring is made at semi solid state, the distribution of the fly ash particles in the molten $\mathrm{Al}$ would not be uniform due to the difference in shear force in the molten slurry. Because the impeller was held concentrically $1 / 3^{\text {rd }}$ height from the bottom of the crucible in the molten slurry. Hence the mixing is limited for the clusters located away from the impeller, resulting in the poor distribution of fly ash particles in the $\mathrm{Al}$ matrix. On the other hand when the second step stirring is done at liquid state, wetted fly ash particles tend to accumulate at the bottom of the crucible due to higher weight density. Hence both the liquid state and two step stirring methods did not have physical and statistical significance.

From the response diagram of $\mathrm{S} / \mathrm{N}$ ratio (Fig. 2 and Fig. 3) it is obvious that the $0.7 \mathrm{I}_{\mathrm{OD}} / \mathrm{C}_{\mathrm{ID}}$ as the optimum ratio in obtaining the maximum mechanical properties of composite. The degree of homogenization depends on the rate of shear flow from the impeller to the clusters which are located away from its position. When the heavier fly ash clusters are subjected to the centrifugal force during stirring through radial impeller with $0.3 \mathrm{I}_{\mathrm{OD}} / \mathrm{C}_{\mathrm{ID}}$, they tend to adhere and deposit on the crucible wall as a thick layer as shown in Fig.4.

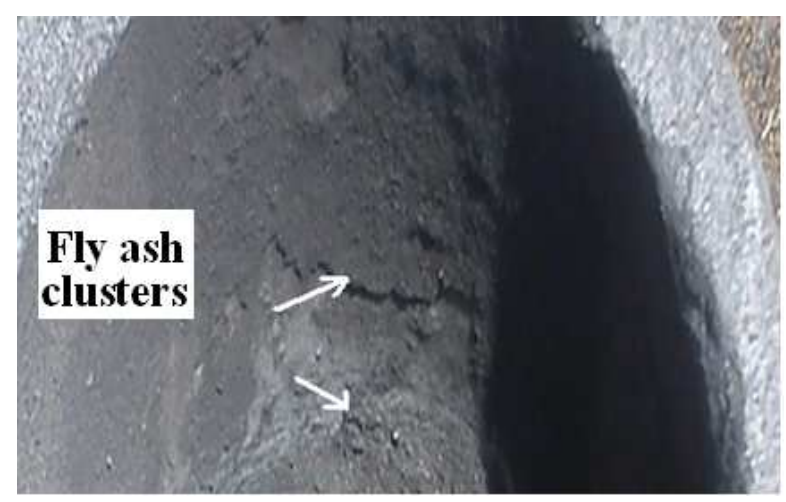

Fig.4

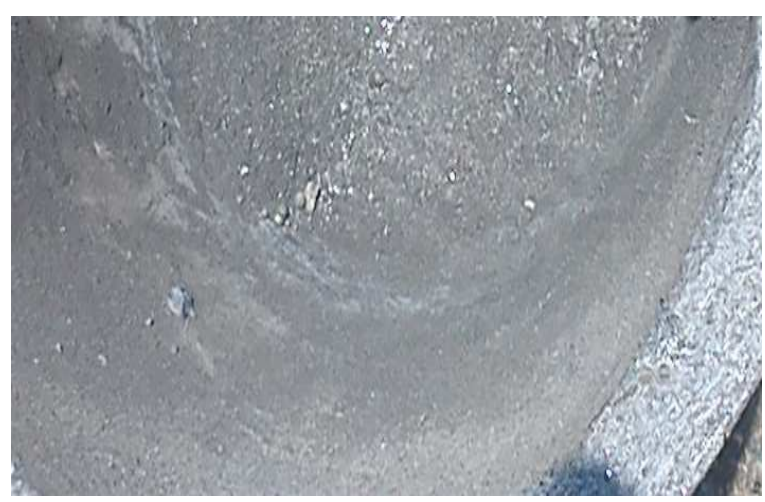

Fig.5

Fig.4 Crucible view (Stirring with $0.3 \mathrm{I}_{\mathrm{OD}} / \mathrm{C}_{\mathrm{ID}}$ ratio)

Fig.5 Crucible view (Stirring with $0.7 \mathrm{I}_{\mathrm{OD}} / \mathrm{C}_{\mathrm{ID}}$ ratio)

As a result, these particles are not returned to the high shear regions of the crucible and the mixing is limited for the clusters located away from the impeller, resulting in the poor distribution of fly ash particles in the $\mathrm{Al}$ matrix. The effect of impeller model can be assessed only with respect to $\mathrm{I}_{\mathrm{OD}} / \mathrm{C}_{\mathrm{ID}}$ ratio. 
Hence the 4 bladed radial impeller with $0.7 \mathrm{I}_{\mathrm{OD}} / \mathrm{C}_{\mathrm{ID}}$ ratio has statistical and physical significance and ensures uniform distribution of fly ash particles in $\mathrm{Al}$ matrix and a little deposit of the slurry on the wall surface of the crucible (Fig.5). It can be concluded that the fly ash wt.\% ,processing method (modified two stepstir casting), 4 bladed radial impeller with $\mathrm{I}_{\mathrm{OD}} / \mathrm{C}_{\mathrm{ID}}$ ratio $(0.7)$ have significant effect on distribution of the fly ash particle in the Al matrix as well as mechanical properties.

\section{Micro Structural Analysis}

Microstructures were examined on the $\mathrm{Al}-15 \mathrm{wt} \%$ fly ash composite samples which were fabricated through modified two step stir casting with $\left(0.7 \mathrm{I}_{\mathrm{OD}} / \mathrm{C}_{\mathrm{ID}}\right.$ ratio $)$ radial impeller using scanning electron microscope. It reveals fly ash particles were distributed more uniformly throughout the whole volume of the specimen and the most of the fly ash particulates was almost perfectly bonded with matrix.This was consequently reflected in the mechanical properties acquired by the tensile and hardness tests carried out.

\section{Conclusions}

The results of $\mathrm{S} / \mathrm{N}$ ratio and ANOVA revealed that the fly ash wt. \% was the most significant parameters followed by processing method and $\mathrm{I}_{\mathrm{OD}} / \mathrm{C}_{\mathrm{ID}}$ ratio. It was found that the optimum parameters were weight percentage of fly ash $(20 \%), \mathrm{I}_{\mathrm{OD}} / \mathrm{C}_{\mathrm{ID}}$ ratio $(0.7)$ and processing method (modified two step stirring) for the hardness whereas weight percentage of fly ash $(15 \%), \mathrm{I}_{\mathrm{OD}} / \mathrm{C}_{\mathrm{ID}}$ ratio (0.7), processing method (modified two step stirring) for the tensile strength of composites.

From the microstructure it was understood that the modified two stepstir casting technique improves the uniform distribution of fly ash particles in the Al. The verification experiment was conducted for the optimum parameters.Best results (maximum hardness $55 \mathrm{BHN}$ and tensile strength $126 \mathrm{MPa}$ ) have been obtained.

The closeness of the results of predictions based on calculated $\mathrm{S} / \mathrm{N}$ ratios and experimental values show that the Taguchi experimental technique can be used successfully for both optimization and prediction.The results indicated that the 'developed method' is successful in obtaining uniform dispersion of fly ash reinforcement in the $\mathrm{Al}$ matrix and maximum mechanical properties.Therefore, by adapting the modified two step stir casting method with relative amount of the reinforcement material, it is possible to obtain a composite with a broad range of mechanical properties.

\section{References}

[1] K.V. Mahendra and K. Radhakrishna: Material science Poland, Vol. 25 (2007), p. 57-68.

[2] S. Sarkar, S. Sen,S.C. Mishra,M.K. Kudelwar and S. Mohan: Journal of reinforced plastics and Composites, Vol.29-1 (2008), p.144-148.

[3] P.K. Rohatgi, D. Weiss and Gupta Nikhil: JOM Vol. 58 (2006), p.71-76

[4] P. Shanmughasundaram, R. Subramanian and G. Prabhu: European Journal of Scientific Research Vol. 63-2 (2011), p. 204-218.

[5] P.K. Rohatgi, J. Sobczak, R. Asthana, J.K. Kim: Mater Sci. Eng A Vol. 252 (1998), p. 98-108.

[6] S. Naher, D. Brabazon, L. Looney: Journal of Materials Processing Technology Vol.143-144 (2003), p. 567-571.

[7] P.K. Ghosh, S. Ray: Indian J. Technology Vol. 26 (1988), p. 83.

[8] N. Aniban, R.M. Pillai, B.C. Pai: Materials and Design Vol. 23(2002), p. 553-556.

[9] F. Rana, B.K. Dhindaw, D.M. Stefanscu: AFS Transactions (1989), p. 255-264.

[10] M.K. Surappa, P.K. Rohatgi: Metals Technology (1978), p. 338-360. 